University of East London Institutional Repository: http://roar.uel.ac.uk

This paper is made available online in accordance with publisher policies. Please scroll down to view the document itself. Please refer to the repository record for this item and our policy information available from the repository home page for further information.

To see the final version of this paper please visit the publisher's website.

Access to the published version may require a subscription.

Author(s): Stone, Anna; Valentine, Tim.

Title: Viewpoint: Perspectives on Prosopagnosia and models of face recognition Year of publication: 2003

Citation: Stone, A., Valentine, T. (2003) 'Viewpoint: Perspectives on Prosopagnosia and models of face recognition.', Cortex, 39 (1), pp.31-40.

Link to published version: http://dx.doi.org/10.1016/S0010-9452(08)70072-8

DOI: 10.1016/S0010-9452(08)70072-8 


\section{Viewpoint: Perspectives on Prosopagnosia and models of face recognition}

Anna Stone and Tim Valentine

Department of Psychology,

Goldsmiths College,

University of London,

UK 


\section{Introduction}

The two papers by Bobes, Lopera, Garcia, Diaz-Comas, Galan and ValdesSosa (2003, this issue) and by Sperber and Spinnler (2003, this issue) add to the large body of literature demonstrating covert face recognition in prosopagnosia. This viewpoint will offer some perspectives on this interesting phenomenon. First, a reanalysis of the empirical literature will indicate an important misconception concerning the preserved abilities of prosopagnosics. The second section will briefly assess the contribution of Bobes et al. (2003, this issue) and Sperber and Spinnler (2003, this issue) to the debate about the locus, in cognitive terms, of the underlying causal deficit in prosopagnosia with covert face recognition. Both papers make reference to the two main models seeking to explain this phenomenon: the model proposed by Burton and colleagues (Burton et al., 1991; Burton and Young, 1999; Young and Burton, 1999) and that proposed by Farah and colleagues (Farah et al., 1993; O'Reilly and Farah, 1999). Finally, an observation will be offered concerning representations of faces in the Burton et al. (1991) model.

\section{Re-analysis of the literature}

Both Bobes et al. (2003, this issue) and Sperber and Spinnler (2003, this issue) state that their participant performed at chance in a task of deciding which of two simultaneously presented faces was familiar; every trial presented one familiar and one unfamiliar face. Failure in this task is central to the definition of prosopagnosia, that is the inability to gain a sense of familiarity to a known face. Other investigations of densely prosopagnosic participants (see Table I) have reported failure in this task. However, participant FE (Bobes et al.) scored 10/16 $=62.5 \%$ correct and participant Emma (Sperber and Spinnler) scored 19/36 $=52.8 \%$ correct. No analysis of power was reported in either case, leaving open the possibility that a test with a sufficient number of trials would have yielded performance better than chance.

A review of the literature, presented in Table I, shows that the majority of densely prosopagnosic participants (9/10) scored above 50\% correct in this task. For illustration, a one-sample t-test with the chance level of performance set at $50 \%$ gives a statistically significant result, $\mathrm{t}(9)=2.07, \mathrm{p}<0.04$ (one-tailed), mean $=55.5$, s.d. $=$ 8.4. The criterion for inclusion in this analysis was that the participant should be unable to gain any subjective sense of familiarity, and unable to provide any semantic information, from visual inspection of the faces of all or virtually all famous people and family members. Thus all the participants had total or near total failure at the early stage of overt familiarity detection as well as the subsequent stage of retrieval of facerelated information. To this extent they present a homogeneous group of participants. Although performance is still severely impaired, and is only just above chance, it may have been premature to conclude that densely prosopagnosic participants cannot detect familiarity in a direct test. Such conclusion relies on acceptance of the null hypothesis and this is particularly problematic without an analysis of power. 
Table 1: Percent correct in the task of deciding which of two simultaneously presented faces is familiar; every trial presented one familiar and one unfamiliar face.

\begin{tabular}{lll} 
Source & Case & Percent correct \\
\hline Bobes et al. (2003) & FE & 63 \\
de Haan, Bauer and Greve (1992) & LF & 51 \\
de Haan, Young and Newcombe (1992) & NR & 75 \\
Diamond, Valentine, Mayes and Sandel (1994) & ET & 53 \\
Newcombe, Young and de Haan (1989) & MS & 53 \\
Sergent and Signoret (1992) & PC & 44 \\
& PM & 54 \\
Sperber and Spinnler (2003) & RM & 58 \\
Young and de Haan (1988) & Emma & 53
\end{tabular}

Note: participants were described as follows: FE "dense prosopagnosia" (p. 9 of manuscript), LF "completely unable to identify familiar people from visual inspection of their faces" (p. 80), NR "identification of familiar faces, whether by naming them or giving appropriate semantic information, was virtually impossible" (p. 147), ET "inability to recognise faces that ought to be familiar" (p. 380), MS "completely unable to recognise familiar faces" (p. 180), PC, PM and RM "severe prosopagnosic" (p. 389), Emma "completely bereft of overt face recognition" (p. 13 of manuscript), PH "completely unable to recognise familiar faces overtly" (p. 320).

The performance of participant $\mathrm{PH}$ in two-alternative forced-choice tasks of occupation decision (Young, 1998) is also informative. When required to select the politician from a pair of faces comprising one politician and one TV personality, with the faces matched on visual characteristics, performance was $55.6 \%$ correct. When required to perform a similar task with just 10 faces repeated 20 times, $\mathrm{PH}$ achieved $52 \%$ correct. When asked to decide whether faces belonged to members of the research team or not, $\mathrm{PH}$ scored $50 \%$ and $56.25 \%$ in two repetitions of the task. Although none of these individual results differs from chance in a binomial test, a onesample t-test on the set of results is very near significance, $t(3)=2.33, p=0.051$ (onetailed), mean $=53.46$, s.d. $=2.97$. The implication is that it may be unwise to draw a conclusion from a single task, and participant $\mathrm{PH}$ may be able to detect occupation in a direct test.

In the light of the suggestion of partially preserved covert familiarity detection it is relevant to examine whether the reported simulations indicate this ability (Burton and Young, 1999; Farah et al., 1993; O'Reilly and Farah, 1999; Young and Burton, 1999). It appears that neither simulation clearly demonstrates above chance performance in 
two-alternative forced-choice tasks of familiarity detection. In the Farah et al. (1993) simulation it is proposed that familiarity may be detected from faster settling into a stable pattern of activation in the case of familiar compared to unfamiliar faces. However, the reported simulations show that the settling speed is similar for familiar and unfamiliar faces at levels of damage where other covert recognition effects are still apparent (p. 52). This does not clearly simulate the apparent preserved capabilities of prosopagnosic participants. Turning to the Burton et al. (1991) model, overt familiarity is signalled by a level of activation at the person identity node (PIN) above a given, arbitrary threshold. Burton and Young (1999) specifically state that there is no mechanism whereby performance in a two-alternative forced-choice test of familiarity can be influenced by a level of activation at the PIN that is below threshold for conscious familiarity detection but above the resting level. "Indeed, as we explicitly discuss in our original article (pp. 18-19) it is a defining characteristic of the model that there is no access to below-threshold activation for the decision mechanism" (p. 78). Thus it appears that both models would require modification to reflect the probable true abilities of prosopagnosics in this regard.

There is another intriguing possibility: that familiarity detection may be based on affective valence rather than on familiarity per se. Greve and Bauer (1990) presented their prosopagnosic participant with pairs of unfamiliar faces, such that in each pair one face had been studied in an earlier phase of the experiment and the other had not. When the task was to select the preferred face, the previously studied face was selected on around $70 \%$ of trials. This is easy to interpret in terms of the mere exposure effect (Zajonc, 1980; see Zajonc, 2001, for a review) which proposes that a familiar item is preferred over an unfamiliar item. In contrast, accuracy was only 53\%, not significantly above chance, when presented with the explicit task of selecting the previously studied face. It seems that accuracy was superior in a preference decision compared to a familiarity decision. This raises the possibility that performance in the familiarity decision is in fact based on preference. Consider a participant with no subjective sense of familiarity to any seen face, who is presented with two faces and asked to pick the previously studied one. The participant has no consciously accessible knowledge on which to base the decision and must guess. It seems plausible that the participant might pick the face in each pair for which there is a preference, whatever the basis for the preference. An explicit preference decision enables the same information to be used more effectively.

The Greve and Bauer (1990) task involved unfamiliar faces, for which only their exposure in the study phase could have generated the participant's preference. For famous faces, however, the situation is quite different, as there is specific knowledge from which an affective attitude towards the person can be derived. Stone et al. (2001, Experiment 3) presented famous faces one at a time to unimpaired participants, for $17 \mathrm{~ms}$ with forward and backward masking preventing conscious recognition. Performance was above chance in a two-alternative forced-choice of "good" versus "evil", defined by the participants' own subsequent ratings, suggesting that affective 
attitude can influence responses to subjectively unknown faces. In a two-alternative forced-choice task of deciding which of two simultaneously presented faces was famous, the prosopagnosic participant (NR) studied by de Haan, Young and Newcombe (1992) consistently chose a subset of the famous faces over several repetitions of the task. At the same time NR had no subjective sense of familiarity to these faces. It is possible that NR's performance was mediated by a positive affective attitude towards these target individuals. It is also possible that other prosopagnosics might show a similar consistency if repeatedly presented with the same stimuli.

To summarise, there is evidence to suggest that affective valence can influence responses to subjectively unknown faces. This could be a fruitful line of research.

\section{Sperber and Spinnler}

Sperber and Spinnler (2003, this issue) document the disappearance of one form of covert face recognition, the true face-name relearning advantage (e.g. Bruyer et al., 1983; see Young, 1998 for a review), in a patient suffering from a degenerative loss of person semantics. The authors point out that this was not prosopagnosia as such, since the deficit in overt person recognition extended to other modalities (e.g. voice and name), and unique person information could not be consciously retrieved via any means. Emma could recognise the names of some celebrities whose faces she deemed unfamiliar, suggesting additional impairment of face recognition as well as the loss of person semantics. This is plausible given that Emma's temporal lobe degeneration was particularly apparent in the right hemisphere.

Sperber and Spinnler suggest that the true face-name relearning advantage observed at the first testing session, with no overt face recognition, implies that person semantics were still accessible but could not be activated to a degree sufficient to enable conscious retrieval by the perception of a known face. The Burton et al. (1991) and the Farah et al. (1993) models both account for covert face recognition in prosopagnosia as the residual functioning of a system that is damaged but not completely obliterated. Tests of covert face recognition are more sensitive to the weakened activation present in a damaged system and hence can be detected in the absence of overt face recognition. The explanation offered by Sperber and Spinnler is clearly the same kind of explanation as those offered by Burton et al. (1991) and Farah et al. (1993): partial activation in a damaged but not obliterated system. It is worth noting, as pointed out by Young and Ellis (2000), that both models would be seriously challenged by an instance of failure to find any form of covert face recognition in the presence of only moderate prosopagnosia. No such case has yet been reported.

Sperber and Spinnler (2003, this issue) add to the literature by extending the observation of true face-name relearning advantage to a participant with a qualitatively different kind of deficit, the loss of person semantics. The paper adds weight to the argument that the same phenomenon of covert face recognition can be due to more than one underlying cause. 


\section{Bobes, Lopera, Garcia, Diaz-Comas, Galan and Valdes-Sosa}

Bobes et al. (2003, this issue) report ERP data from a prosopagnosic participant, FE, impaired in the overt sequential matching of 2 photographs of a previously unfamiliar face when these differed in emotional expression. Yet the ERP data distinguished between match and mismatch trials with the same latency as an age-matched control group, suggesting dissociation between overt and covert performance in this task. The authors suggest that FE presents normal early face perception and a normal availability of face structural codes. This contradicts the Farah et al. (1993) model of covert face recognition in prosopagnosia, which predicts that there will always be impairment of early face perception. Bobes et al. (2003, this issue) refer to the Burton (1994) model incorporating a learning mechanism, in which weak and temporary face recognition units (FRUs) are formed for new faces. The weak and temporary FRU created for the first face in each pair could enable the covert detection of mismatch. The authors "speculate that activation of PINs, or other nodes..., are necessary for the explicit encoding of face information into working memory which would enable overt matching". Thus it is suggested that the deficit in overt sequential matching of unfamiliar faces may stem from the same underlying cause as the deficit in overt familiar face recognition: damage to connections between intact FRUs and PINs.

Relevant to the "explicit encoding of face information into working memory" is the investigation of face imagery reported by Cabeza et al. (1997). They proposed the existence of two separate links between FRUs and PINs: the link from the FRU to the PIN supports recognition, while the link from the PIN to the FRU supports imagery (face recall). The results reported by De Renzi and Pellegrino (1998) and by Takahashi et al. (1995) are compatible with this interpretation. In regards to Bobes et al. (2003, this issue), access to the first face in a pair could be achieved via the PIN, linking to the FRU in order to encode into working memory an image of the first face for comparison with the second face. If the link from the PIN to the FRU were damaged but not obliterated then this process would be somewhat impaired, which could result in the covert but not overt sequential matching of unfamiliar faces.

This account clearly supports the Burton et al. (1991) account of covert face recognition in prosopagnosia rather than the Farah et al. (1993) model. However, there is an alternative explanation. The faces in each pair were presented for $1000 \mathrm{~ms}$ each with no inter-stimulus interval. The immediate presentation of the second face allows the possibility that the structural representation of the first face was held in working memory and never established as a stored record. There is therefore insufficient evidence to establish that FRUs were created. In addition, Bobes et al. noted that "The general morphology of the ERPs in FE is somewhat different to the grand average of the control group, specially due to the presence of a larger N170 at posterior and temporal sites". This suggests that the early processes of face perception may not have been entirely normal in FE, and is consistent with the Farah et al. (1993) model. 
An additional consideration is the contradiction between Bobes et al. (2003) and Bobes et al. (1999). The earlier paper also reported the results of an ERP study of participant FE but reached the contrasting conclusion that FRUs were impaired. The discrepancy may be resolved by considering that the task presented by Bobes et al. (1999) relied on face structural information held in long-term memory, whereas the task presented by Bobes et al. (2003, this issue) did not. This permits an alternative account, as follows. Participant FE is impaired both in the process of constructing a structural representation of a perceived face and in the long-term storage of face records. The achievement of an impaired representation of an unfamiliar face explains covert success and overt failure in the immediate sequential matching of unfamiliar faces. Impairment to the store of face records explains covert and overt failure in the task of Bobes et al. (1999) that required long-term storage. This implies damage to early face perception and to the stage of storing structural face representations and is thus consistent with the Farah et al. (1993) model.

One point that must be made is that interpretation of tasks involving unfamiliar faces in terms of models of familiar face recognition necessitates the assumption that unfamiliar and familiar faces are processed by the same system. If this is not the case then any data on unfamiliar face matching is uninformative about prosopagnosia. For example, a sequential matching task on unfamiliar faces (e.g. Bobes et al., 2003, this issue) might rely only on the structural encoding stage and some other system involving the temporary storage of an abstract structural record of an unfamiliar face. Note that structural encoding must be a common stage for familiar and unfamiliar faces since it is only after this stage that a face can be categorised as familiar.

It should be made clear quite what is meant by saying that familiar and unfamiliar faces are "processed in the same system". The processing involved in unfamiliar faces requires that a structural record of the face is created and stored so that it can be accessed in future, with the attachment of minimal semantic information detailing the situation in which the face has been encountered. No other semantic information is available for an unfamiliar face.

While there is evidence of double dissociation of impairment between the processing of familiar and unfamiliar faces (e.g. Parry et al., 1991; Young et al., 1993; see e.g. Bruce and Young, 1998; Hancock et al., 2000, for reviews) this does not suffice to establish that separate cognitive systems are involved. It is important to note that different tasks are used to investigate the processing of familiar and unfamiliar faces. Typically, unfamiliar faces are presented in a task of simultaneous or sequential matching of same or different views of the same face, or in a task of deciding whether or not an unfamiliar face was presented during an earlier study phase. At most, unfamiliar faces must be remembered for an hour or two. Familiar faces, in contrast, are presented for familiarity decision or retrieval of information about the target individual (e.g. Bruce and Young, 1998) and this demands that a face be remembered over a much longer period. Therefore tasks performed on familiar and unfamiliar faces do not place equivalent demands on memory. There is evidence that prosopagnosics 
have the ability to remember faces for the duration of an experiment but not for longer periods. Several researchers (de Haan et al., 1987; 1991; Diamond et al., 1994; McNeil and Warrington, 1991; Schweinberger et al., 1995; Sergent and Poncet, 1990; Sergent and Signoret, 1992; Young and de Haan, 1988) have demonstrated that facename and face-occupation pairings can be learned after several repetitions. This shows that a face can be overtly associated with a name or an occupation for short time. However, this learning is only temporary, or prosopagnosia would be a transient condition. If there is impairment to the long term storage of structural face records, unfamiliar face processing may be relatively preserved in a task requiring that the face records be stored only temporarily (for the duration of an experiment) while familiar face recognition is severely impaired.

Another difference concerns the quality of representation required for the recognition of familiar faces compared to unfamiliar faces. Hancock et al. (2000) review evidence that familiar faces can be recognised from very poor quality photographs, while unfamiliar faces cannot. If there is impairment to the structural encoding stage, conceptually equivalent to a poor quality photograph, then processing of unfamiliar faces may be severely impaired, while the recognition of familiar faces and recall of semantic information can still be achieved with substantial success.

The observation in some prosopagnosics of relatively preserved processing of unfamiliar faces combined with severe impairment of familiar face recognition, and the opposite pattern in other participants, may be partially due to the unequal difficulty of the tasks typically employed. Hence the observed double dissociation of performance deficits between the processing of familiar and unfamiliar faces does not constitute evidence of separate cognitive systems. The principle of parsimony suggests that a single system for processing familiar and unfamiliar faces should be assumed in the absence of strong evidence to the contrary. To show how this might work, Burton (1994) describes and simulates a process for face learning that implicates only one system.

\section{An observation on the Burton et al model}

The Burton et al. (1991) model contains two representations of names: the name input units subserving recognition, and the name semantic units subserving recall. The relative difficulty of name recall compared to name recognition is accounted for by the extra step required to access the name semantic unit for name recall. A similar empirical phenomenon applies also to faces, that is recognition is easier than recall, assuming face imagery to be the equivalent of face recall (e.g. Cabeza et al., 1997). Yet the same Burton et al. (1991) model, enhanced in Cabeza et al. (1997), represents structural information about a face only once, in the FRU. A single store of structural information about faces is supported by fMRI evidence (e.g. O'Craven and Kanwisher, 2000) and by behavioural data (e.g. Cabeza et al., 1997; Michelon and Koenig, 2002) suggesting that face perception and face imagery share common representations and processing mechanisms (see Kosslyn, 1994; 1995 for reviews). 
Cabeza et al. (1997) account for the superiority of face recognition over recall by two separate links between FRU and PIN such that the link from FRU to PIN subserving face recognition is more easily activated than the link from PIN to FRU subserving recall.

An even more parsimonious account has only one link between FRU and PIN. The superiority of face recognition over recall can be understood by observing that recognition requires access from the complex code specifying the structure of the face to a single entry, the PIN, whereas recall requires access from the PIN to reconstruct the complex code. It seems plausible that the former is easier than the latter. The results of Cabeza et al. (1997) that were interpreted as implying two separate links between FRU and PIN may in fact be consistent with a single link, with the additional observation that their perceptual and imagery tasks seem likely to have used different subsets of the information stored in the FRU. The perception of very familiar faces is likely to have concentrated on internal features whereas imagery, a harder task, may have concentrated on more readily imaged aspects of a face such as external features (e.g. hair) and distinguishing marks.

At a simple level it would seem that the superiority of face recognition over face imagery may be explained either by the existence of two separate links between FRU and PIN, or by one link with access in two directions. A relevant consideration is the principle of parsimony at the level of neural implementation, and it seems probable that the most efficient implementation would be a single link. Perhaps detailed theoretical and empirical consideration could be given to this question.

Returning to names, Valentine et al. (1996) proposed a single lexical store. This was supported by the results of two experiments (Valentine et al., 1998; replicated by Hollis and Valentine, 2001) that cannot be explained in the Burton et al. (1991) model. The Valentine et al. (1996) model did, however, retain separate input and output stores for phonological representations of names. It is also interesting that part of the debate between Burton and colleagues (Burton et al., 1991; Burton and Young, 1999; Young and Burton, 1999) and Farah and colleagues (Farah et al., 1993; O'Reilly and Farah, 1999) concerned the question of a single representation of names versus separate representations for input and output. Perhaps consideration could be given to the possibility of moving towards a single lexical store of names, along the lines of a single store of face structural representations.

\section{Conclusions}

A number of conclusions can be drawn from this Viewpoint that challenge the prevailing views of prosopagnosia and models of face recognition. First, a level of familiarity detection not significantly better than chance in a single case study does not necessarily serve to establish the complete absence of preserved ability, and it appears that densely prosopagnosic participants may have some covert ability to detect familiarity in a direct test. Second, the question of facial familiarity detection in 
prosopagnosia has been posed in terms of familiarity per se, but the data from the prosopagnosic participant studied by Greve and Bauer (1990) suggests that affective attitude rather than familiarity may be the stronger influence on responses. As a general point, affective judgements do not appear to have been investigated in prosopagnosics: perhaps this would be a fruitful line for future research. Finally, the question of how structural information about faces is represented and accessed seems worthy of detailed investigation.

\section{References}

BOBES, M.A., LOPERA, F., GARCIA, M., DIAZ-COMAS, L., GALAN, L. \& VALDES-SOSA, M. Covert matching of unfamiliar faces in a case of prosopagnosia: An ERP study. Cortex, 2003.

BOBES, M.A., VALDES-SOSA, M., GARCIA, M., GOMEZ, J.F. \& LOPERA, F. ERP signs of abnormal face processing in prosopagnosia. Brain and Cognition, 40: 5257, 1999.

BRUCE, V. \& YOUNG, A.W. A theoretical perspective for understanding face recognition. In A.W. Young (Ed.), Face and Mind. Oxford: Oxford University Press, 1998, Ch. 3, pp. 96-130.

BRUYER, R., LATERRE, C., SERON, X., FEYEREISEN, P., STRYPSTEIN, E., PIERRARD, E. \& RECTEM, D. A case of prosopagnosia with some preserved covert remembrance of familiar faces. Brain and Cognition, 2: 257-284, 1983.

BURTON, A.M. Learning new faces in an interactive activation and competition model. Visual Cognition, 1: 313-348, 1994.

BURTON, A.M. \& YOUNG, A.W. Simulation and explanation: Some harmony and some discord. Cognitive Neuropsychology, 16: 73-77, 1999.

BURTON, A.M., YOUNG, A.W., BRUCE, V., JOHNSTON, R.A. \& ELLIS, A.W. Understanding covert recognition. Cognition, 39: 129-166, 1991.

CABEZA, R., BURTON, A.M., KELLY, S.W. \& AKAMATSU, S. Investigating the relation between imagery and perception: Evidence from face priming. Quarterly Journal of Experimental Psychology: Human Experimental Psychology, 2: 274-289, 1997.

DE HAAN, E.H., BAUER, R.M. \& GREVE, K.W. Behavioural and physiological evidence for covert face recognition in a prosopagnosic patient. Cortex, 28: 77-95, 1992.

DE HAAN, E.H.F., YOUNG, A.W. \& NEWCOMBE, F. Face recognition without awareness. Cognitive Neuropsychology, 4: 385-415, 1987. 
DE HAAN, E.H.F., YOUNG, A.W. \& NEWCOMBE, F. Covert and overt recognition in prosopagnosia. Brain, 114: 2575-2591, 1991.

DE HAAN, E.H.F., YOUNG, A.W. \& NEWCOMBE, F. Neuropsychological impairment of face recognition units. Quarterly Journal of Experimental Psychology: Human Experimental Psychology, 44A: 141-175, 1992.

DE RENZI, E. \& PELLEGRINO, G. Prosopagnosia and alexia without object agnosia. Cortex, 34: 403-415, 1998.

DIAMOND, B.J., VALENTINE, T., MAYES, A.R. \& SANDEL, M.E. Evidence of covert recognition in a prosopagnosic patient. Cortex, 30: 377-393, 1994.

FARAH, M.J., O'REILLY, R.C. \& VECERA, S.P. Dissociated overt and covert recognition as an emergent property of a lesioned neural network. Psychological Review, 100: 571-588, 1993.

GREVE, K.W. \& BAUER, R.M. Implicit learning of new faces in prosopagnosia: an application of the mere-exposure paradigm. Neuropsychologia, 28: 1035-1041, 1990.

HANCOCK, P.J.B., BRUCE, V. \& BURTON, A.M. Recognition of unfamiliar faces. Trends in Cognitive Sciences, 4: 330-337, 2000.

HOLLIS, J. \& VALENTINE, T. Proper-name processing: Are proper names pure referencing expressions? Journal of Experimental Psychology: Learning, Memory and Cognition, 27: 99-116, 2001.

KOSSLYN, S.M. Image and brain: The resolution of the imagery debate. Cambridge, Massachusetts: MIT Press, 1994.

KOSSLYN, S.M. Mental imagery. In SM Kosslyn and DN Osherson (Eds.), Visual Cognition: An invitation to cognitive science. 1995, Ch. 7, pp. 267-296.

MCNEIL, J.E. \& WARRINGTON, E.K. Prosopagnosia: A reclassification. The Quarterly Journal of Experimental Psychology, 43A: 267-287, 1991.

MICHELON, P. \& KOENIG, O. On the relationship between visual imagery and visual perception: Evidence from priming studies. European Journal of Cognitive Psychology, 14: 161-184, 2002.

NEWCOMBE, F., YOUNG, A.W. \& DE HAAN, E.H.F. Prosopagnosia and object agnosia without covert recognition. Neuropsychologia, 27: 179-191, 1989.

O'CRAVEN, K.M. \& KANWISHER, N. Mental imagery of faces and places activates corresponding stimulus-specific brain regions. Journal of Cognitive Neuroscience, 12: 1013-1023, 2000. 
O'REILLY, R.C. \& FARAH, M.J. Simulation and explanation in neuropsychology and beyond. Cognitive Neuropsychology, 16: 49-72, 1999.

PARRY, F.M., YOUNG, A.W., SAUL, J.S. \& MOSS, A. Dissociable face processing impairments after brain injury. Journal of Clinical and Experimental Neuropsychology, 13: 545-558, 1991.

SCHWEINBERGER, S.R., KLOS, T. \& SOMMER, W. Covert face recognition in prosopagnosia: A dissociable function. Cortex, 31: 517-529, 1995.

SERGENT, J. \& PONCET, M. From covert to overt recognition of faces in a prosopagnosic patient. Brain, 113: 989-1004, 1990.

SERGENT, J. \& SIGNORET, J.L. Implicit access to knowledge derived from unrecognised faces in prosopagnosia. Cerebral Cortex, 2: 389-400, 1992.

SPERBER, S. \& SPINNLER, H. Covert person recognition: Its fadeout in a case of temporal lobe degeneration. Cortex, 2003.

STONE, A., VALENTINE, T. \& DAVIS, R. Face recognition and emotional valence: Processing without awareness by neurologically intact participants does not simulate covert recognition in prosopagnosia. Cognitive, Affective and Behavioural Neuroscience, 1: 183-191, 2001.

TAKAHASHI, N., KAWAMURA, M., HIRAYAMA, K., SHIOTA, J. \& ISONO, O. Prosopagnosia: A clinical and anatomical study of four patients. Cortex, 31: 317-329, 1995.

VALENTINE, T., BRENNEN, T. \& BREDART, S. The cognitive psychology of proper names: On the importance of being Ernest. London: Routledge, 1996.

VALENTINE, T., HOLLIS, J. \& MOORE, V. On the relationship between reading, listening and speaking: It's different for people's names. Memory and Cognition, 26: 740-753, 1998.

YOUNG, A.W. Covert face recognition in prosopagnosia. In AW Young (Ed.), Face and Mind. Oxford: Oxford University Press, 1998, Ch. 11, pp. 282-312.

YOUNG, A.W. \& BURTON, A.M. Simulating face recognition: Implications for modelling cognition. Cognitive Neuropsychology, 16: 1-48, 1999.

YOUNG, A.W. \& DE HAAN, E.H.F. Boundaries of covert recognition in prosopagnosia. Cognitive Neuropsychology, 5: 317-336, 1988.

YOUNG, A.W. \& ELLIS, H.D. Overt and covert face recognition. In Y Rossetti and A Revunsuo (Eds.), Beyond Dissociation: Interference Between Dissociated Implicit and Explicit Processing. Amsterdam: Benjamins, 2000, Ch. 9, pp. 195-220. 
YOUNG, A.W., NEWCOMBE, F., DE HAAN, E.H.F., SMALL, M. \& HAY, D.C. Face perception after brain injury: Selective impairments affecting identity and expression. Brain, 116: 941-959, 1993.

ZAJONC, R.B. Feeling and thinking: Preferences need no inferences. American Psychologist, 35: 151-175, 1980.

ZAJONC, R.B. Mere exposure: A gateway to the subliminal. Current Directions in Psychological Science, 10: 224-228, 2001. 